\title{
FLUKTUASI FOSPOR DAN KEMASAMAN PADA AGREGAT TANAH DI PERKEBUNAN TEH YANG BERUMUR 36 TAHUN DI KECAMATAN GUNUNG TALANG, KABUPATEN SOLOK
}

\section{Phosphorus and Acidity Fluctuation in Soil Aggregates in 36-years Cultivation of Tea Plantation, at Gunung Talang District, Solok Regency}

\author{
Bori Heria Fadli*, Syafrimen Yasin, Yulnafatmawita \\ Program Studi Ilmu Tanah, Fakultas Pertanian, Universitas Andalas, Limau Manis, Padang, 25163 \\ *Penulis korespondensi: boriheriafadli@gmail.com
}

\begin{abstract}
Soil acidity is the dominant factor in the phosphate amount, distribution of nutrients in the aggregate is important to supporting nutrient requirement and cycling. Furthermore, Al-P and Fe-P or Ca-P bonds trapped in soil minerals, also physically protected from loss due to associate with aggregates. Thus, the factual limitation of phosphorus becomes a topic, including various aggregate fractions changes and their effect on the slope. Soil samples were taken from 36 years old plantations consisting of 45 points with two depths $(0-20 \mathrm{~cm}$ and $20-40 \mathrm{~cm})$ on a various slope, soil samples fractionated into several aggregate fractions, namely micro $(<250 \mu \mathrm{m})$, meso $(250-2000 \mu \mathrm{m})$ and macro-aggregates $(2,000-5,000 \mu \mathrm{m})$. For chemical analysis, soil $\mathrm{pH}$ was measured by $\mathrm{pH}$ meter, aluminium with the volumetric method, and $\mathrm{P}$-available with Bray method. Based on the analysis, it is known that the $\mathrm{P}$ content in the meso aggregate is higher than $\mathrm{P}$ content in the macro aggregate $\pm 0.055 \mathrm{~g} \mathrm{~m}^{-2}$ for 0 $20 \mathrm{~cm} \pm 2.136 \mathrm{~g} \mathrm{~m}^{-2}$ for $20-40 \mathrm{~cm}$ depth, and $\pm 1.058 \mathrm{~g} \mathrm{~m}^{-2}$ for slope of $0-8 \%$ at $0-20 \mathrm{~cm}$ depth. In total, phosphate in the tea plantation area is very low.
\end{abstract}

Keywords: acidity, aggregates fraction, phosphate, slope

\section{Pendahuluan}

Teh adalah tanaman yang spesial yang cocok ditanam pada tanah masam, namun juga menyumbangkan kemasaman tanah (Yan et al., 2018). Kemasaman tanah adalah faktor dominan dalam ketersediaan fosfat, karena umumnya fosfat terlarut dalam tanah berbentuk anion maka akan sangat mudah berikatan dan terjerap oleh mineral liat sehingga tidak tersedia bagi tanaman. Distribusi hara dalam agregat penting dalam mendukung kebutuhan hara dan siklus hara, terutama fosfor yang ketersediaannya sangat penting dalam metabolisme tanaman.

Fosfor adalah unsur yang penting yang dibutuhkan tanaman setelah $\mathrm{N}$, dengan jumlah $2-0,05 \%$ dalam berat kering tanaman atau setara 2-5 kg. Perkebunan teh yang membutuhkan Aluminium dalam jumlah besar sekaligus menjadi faktor yang memasamkan tanah, yang pada proses pertumbuhannya akan sangat mempengaruhi ketersedian fosfat pada tanah dalam memenuhi kebutuhan fosfat. Ketersediaan P biasanya dijerap oleh mineral liat dalam bentuk orthofosfate, yang biasanya oleh ikatan seskuioksida (seperti $\mathrm{Fe}$ dan $\mathrm{Al}$ ). Faktor penyebab ketidaktersediaan $\mathrm{P}$ pada tanah cukup komplek termasuk larutan tanah, tergantung waktu, $\mathrm{pH}$, kelembapan, mineralogi, dan aktivitas mikroorganisme (Peoples, 2014). Lebih dari $80 \% \mathrm{P}$ yang diaplikasikan ke tanah tidak terserap oleh tanaman, karena terjerap oleh $\mathrm{Al}$ dan Fe pada tanah masam, dan Ca pada tanah alkali, ataupun karena immobolisasi mikroba (Zhu et al., 2018).Lebih lanjut, ikatan Al-P dan Fe-P ataupun Ca-P yang terjerap pada mineral tanah yang secara fisik juga terlindungi dari 


\section{Jurnal Tanah dan Sumberdaya Lahan Vol 8 No 1: 215-219, 2021 e-ISSN:2549-9793, doi: 10.21776/ub.jts1.2021.008.1.24}

kehilangan karena terasosiasi dengan agregat tanah. Disamping itu, $\mathrm{P}$ yang tidak terikat dan terlarut di larutan tanah akan mudah hilang melalui run off dan leaching yang juga tergantung pada kekasaran partikel melalui celah, retakan, ataupun tanah yang bertekstur pasir.

Kekasaran partikel yang membentuk agregat mempengaruhi jumlah dan ketersediaan fosfor, termasuk fosfor yang terikat kuat ataupun lemah bersama aluminium. PPTK (2019) Kandungan hara P tanaman teh di unit usaha danau kembar tergolong sangat rendah (< 4 ppm), sedangkan $\mathrm{N}, \mathrm{K}$, dan $\mathrm{Mg}$ berkriteria sedang sampai sangat tinggi. Hal ini karena tanaman teh mengakumulasi $\mathrm{Al}$ pada daun dan akan terurai melalui proses biogeokimia melalui daun yang terurai pada permukaan tanah (Yan et al., 2018). Disamping itu, pemupukan N pada teh juga dapat menyumbangkan kemasaman, karena tanaman teh mengambil $\mathrm{N}$ dalam bentuk ammonium, sehingga menghasilkan $\mathrm{H}^{+}$dalam prosesnya. Dengan demikian, keterbatasan ketersediaan fosfor yang dipengaruhi oleh banyak faktor menjadi topik yang dibahas termasuk perubahannnya dalam berbagai fraksi agregat dan pengaruhnya terhadap kelerengan.

\section{Bahan dan Metode}

\section{Sampel tanah}

Pada penelitian ini, sampel diambil pada perkebunan teh yang dikelola oleh rakyat di dua nagari yaitu batang barus dan aia batumbuk kecamatan Gunung Talang, Kabupaten Solok. Secara geografis lokasi penelitian ini berada di Kecamatan Gunung Talang yaitu antara00 $52^{\circ}$ 33" LS sampai $01^{0} 04^{\prime} 40^{\prime \prime}$ LU dan $100^{\circ} 31^{\prime} 34^{\prime \prime}$ sampai $100^{\circ} 41^{\prime} 58^{\prime \prime}$ BT dengan ketinggian tempat diatas $1500 \mathrm{~m}$ di atas permukaan laut (mdpl)., dengan curah hujan $\pm 2000 \mathrm{~mm}$ per tahun. Perkebunan teh rakyat yang berada di Nagari Batang Barus dan Nagari Aia Batumbuak memiliki luas 336.15 dari total 443 ha. Sampel tanah diambil di perkebunan teh yang berumur 36 tahun yang terdiri atas 45 titik dengan dua kedalalam $(0-20 \mathrm{~cm}$ dan $20-40 \mathrm{~cm})$ pada lereng $0-8 \%, 8-15 \%, 15-25 \%, 25-45 \%$, dan $>45 \%$. Untuk kebutuhan analisis sifat kimia di laboratorium, hanya membutuhkan sampel tanah terganggu.

\section{Fraksionasi tanah}

Sampel agregat utuh dikering anginkan terlebih dahulu, kemudian di masukan ke ayakan kering dengan urutan ayakan $(4.75 \mathrm{~mm}, 2.8 \mathrm{~mm}, 2 \mathrm{~mm}$, $1 \mathrm{~mm}, 500 \mu \mathrm{m}$, dan 53 mesh ), lalu sampel di pisahkan menjadi beberapa fraksi agregat yaitu mikro $(<250 \mu \mathrm{m})$, meso $(250-2000 \mu \mathrm{m})$ dan makro-agregat (2000-5000 $\mu \mathrm{m})$. Perhitungan kandungan hara per ukuran agregat Nutrient Pool (NP, $\mathrm{g} \mathrm{m}^{-2}$ ) dengan menggunakan perhitungan Yang et al. (2007) sebagai berikut,

$\mathrm{NP}=\sum_{i=1}^{3}(\mathrm{n} i \mathrm{xhh} i) \times \mathrm{BV} \times \mathrm{H} \times 10$

Dimana (n) adalah proporsi ukuran fraksionasi pada tanah (\%), (hh) hasil analisis hara per fraksi $\left(\mathrm{g} \mathrm{kg}^{-1}\right)$, BV adalah bulk density $\left(\mathrm{g} \mathrm{cm}^{-3}\right)$, dan $\mathrm{H}$ adalah ketebalan tanah $(\mathrm{cm})$. Semua hasil analisis kimia pada tiap fraksi agregat dapat dihitung dengan cara yang sama.

\section{Analisis sifat fisika dan kimia tanah}

Setelah dilakukan fraksionasi agregat, maka tanah di oven pada suhu $105^{\circ} \mathrm{C}$ untuk memperoleh berat kering mutlak yang dipakai untuk pengukuran $\mathrm{BV}$. Untuk analisis kimia, $\mathrm{pH}$ tanah diukur $\mathrm{pH}$ meter, dan aluminium dapat ditukar denagn metode volumetri, dan Ptersedia dengan metode Bray (BPT, 2005).

\section{Hasil dan Pembahasan}

\section{Pasokan hara fosfat pada fraksi agregat}

Berdasarkan hasil analisis yang disajikan pada Tabel 1, diketahui bahwa kandungan fosfat pada tanah perkebunan teh tertinggi terdapat pada fraksi makro agregat di kelerengan 0-8\% pada kedalaman $20-40 \mathrm{~cm}$ dan kelerengan $15-25 \%$ pada kedalaman $0-20 \mathrm{~cm}$ dengan nilai berturutturut $1,429 \mathrm{~g} \mathrm{~m}^{-2}$ dan $1,407 \mathrm{~g} \mathrm{~m}^{-2}$. Pada agregat Meso, P tersedia tertinggi terdapat kelerengan 08\% pada kedalamaan 0-20 dengan nilai 7,346 g $\mathrm{m}^{-2}$, dengan nilai terendah terdapat pada kelerengan $25-45 \%$ pada kedalaman 20-40 dengan nilai $1,38 \mathrm{~g} \mathrm{~m}^{-2}$.

Pada makro agregat tertinggi terdapat pada kerengan $0-8 \%$ pada kedalaman 20-40 dengan nilai $10,627 \mathrm{~g} \mathrm{~m}^{-2}$, dan $8-15 \%$ pada kedalaman 020 dengan 10,835 $\mathrm{g} \mathrm{m}^{-2}$ (Gambar 1). Secara keseluruhan fosfat pada daerah perkebunan teh 
berada pada kriteria yang sangat rendah. Kekasaran agggergat pada perkebunan tanaman teh tidak secara otomatis mempengaruhi jumlah ketersediaan P, pada kelerengan $15-25 \%$ untuk semua kedalaman kandungan $\mathrm{P}$ pada meso agregat lebih tinggi dari kandungan $\mathrm{P}$ pada makro agregat $\pm 0.055 \mathrm{~g} \mathrm{~m}^{-2}$ untuk $0-20 \mathrm{~cm}, \pm$ 2,136 $\mathrm{g} \mathrm{m}^{-2}$ untuk kedalaman $20-40 \mathrm{~cm}$, dan \pm $1,058 \mathrm{~g} \mathrm{~m}^{-2}$ untuk kelerengan $0-8 \%$ pada kedalaman $0-20 \mathrm{~cm}$.

Tabel 1. Hasil analisis tanah perkebunan teh.

\begin{tabular}{|c|c|c|c|c|c|c|c|}
\hline \multirow[t]{3}{*}{ Analisis } & \multirow{3}{*}{$\begin{array}{c}\text { Kelas } \\
\text { Lereng }\end{array}$} & \multicolumn{6}{|c|}{ Fraksi Agregat } \\
\hline & & Mikro & Meso & Makro & Mikro & Meso & Makro \\
\hline & & \multicolumn{3}{|c|}{$0-20 \mathrm{~cm}$} & \multicolumn{3}{|c|}{$20-40 \mathrm{~cm}$} \\
\hline \multirow[t]{5}{*}{ P-supply $\left(\mathrm{g} \mathrm{m}^{-2}\right)$} & $0-8 \%$ & 0,593 & 7,346 & 6,288 & 1,429 & 2,707 & 10,627 \\
\hline & $8-15 \%$ & 0,679 & 3,709 & 10,835 & 0,484 & 2,973 & 4,742 \\
\hline & $15-25 \%$ & 1,407 & 4,031 & 3,976 & 0,535 & 4,067 & 1,931 \\
\hline & $25-45 \%$ & 0,282 & 2,796 & 4,506 & 0,617 & 1,38 & 5,677 \\
\hline & $>45 \%$ & 0,535 & 2,454 & 4,676 & 0,228 & 1,636 & 2,456 \\
\hline $\mathrm{BV}\left(\mathrm{g} \mathrm{cm}^{-3}\right)$ & & & 0,54 & & & 0,42 & \\
\hline C-organik (\%) & & 12,462 & 11,768 & 11,291 & 5,858 & 4,834 & 6,371 \\
\hline $\mathrm{pH}\left(\mathrm{H}_{2} \mathrm{O}\right)$ & & 4,397 & 4,359 & 4,403 & 4,392 & 4,412 & 4,471 \\
\hline Kejenuhan & & 41,235 & 41,306 & 38,048 & 15,471 & 18,338 & 10,554 \\
\hline Aluminium (\%) & & & & & & & \\
\hline
\end{tabular}

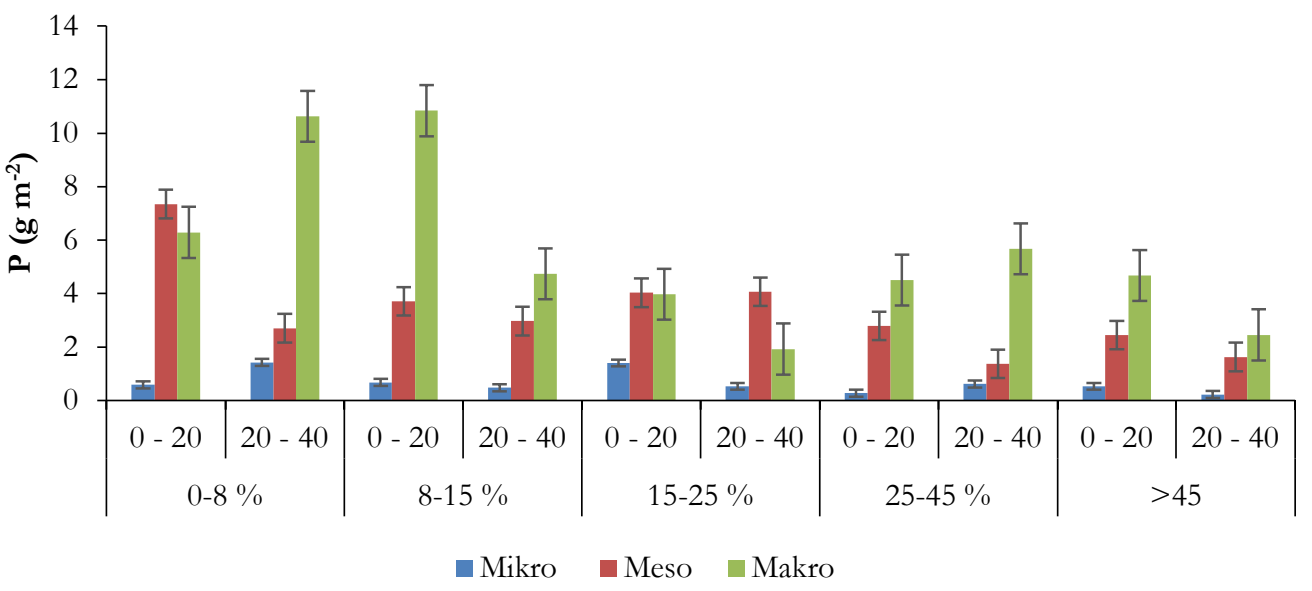

Gambar 1. Pasokan P per-kedalaman berdasarkan kemiringan lahan.

Faktor budidaya jangka panjang secara intensif mempunyai peranan yang penting terhadap penurunan kandungan fosfat pada tanah perkebunan teh. Pengelolaan lahan dengan manejemen jarak tanam pada setiap kelerengan pada perkebunan teh, akan memberi pengaruh pada jumlah sumbangan bahan organik pada perkebunan teh. Untuk kelerengan $0-15 \%$ jarak tanam $120 \times 90 \mathrm{~cm}, 15-30 \%$ jarak tanam $120 \mathrm{x}$
$75 \mathrm{~cm}$, kelerengan $>30 \%$ dan jarak tanam 120 x $75 \mathrm{~cm}$, dengan populasi berturut turut 9.620 , 11.110, dan 13.888 populasi (Puslitbangkeb, 2010). Maka semakin besar jumlah populasi, tajuk tanaman akan semakin rapat, sehingga penumpukan bahan organik juga semakin tinggi. Bahan organik juga manjadi salah satu faktor yang memainkan peran penting yang mempengaruhi jumlah hara per fraksi agregat. 


\section{Jurnal Tanah dan Sumberdaya Lahan Vol 8 No 1: 215-219, 2021 e-ISSN:2549-9793, doi: 10.21776/ub.jts1.2021.008.1.24}

Sifat bahan organik yang sebagai agen perekat antar partikel tanah dan sebagai penyumbang hara bermuatan (-), akan sangat mempengaruhi penjerapan $\mathrm{P}$. Tingginya $\mathrm{OH}^{-}$pada tanah membuat $\mathrm{P}$ yang juga berbentuk anion sulit terjerap pada ikatan organo komplek antar agregat. Sehingga $\mathrm{P}$ akan hilang melalui pencucian ataupun terikat kuat oleh ikatan Al-P, Fe-P, ataupun ikatan Ca-P. Bagaimanapun, kemungkinan penurunan P organik pada agregat terhambat karena adanya perubahan $\mathrm{P}$ organik terjerap oleh oksida oksida (Garland et al., 2018).

Pada perkebunan teh yang telah berumur 36 tahun, selain manajemen lahan terutama pada pengolahan, ameliorasi juga tanah cenderung menurunkan ketersediaan $\mathrm{P}$ pada tanah perkebunan. Penurunan ketersediaan P pada fraksi agregat yang telah terakumulasi selama bertahun-tahun pada perkebunan teh terlihat dengan rendahnya nilai $\mathrm{pH}$ tanah pada kedalaman 0-20 dan 20-40 cm (Tabel 1), setelah aplikasi $\mathrm{P}$, perombakan $\mathrm{P}$ menjadi terlarut sangat cepat termineralisasi dan terjerap oleh mineral dan mikroorganisme (Zheng et al., 2011).

Aluminium merupakan permasalahan utama terhadap rendahnya kandungan $\mathrm{P}$ pada tanah perkebunan teh. Bagi tanaman teh, yang cenderung mengkonsumsi $\mathrm{Al}$, pangakasan dan panen adalah sumber sumbangan $\mathrm{Al}$ melalui akumulasi bahan organik pada tanah. Melalui siklus biogeokimia pada daun teh dapat menyebabkan pemasaman tanah dari akumulasi Al pada daun teh (Yan et al., 2018). Penurunan
$\mathrm{pH}$ tanah dan meningkatnya jumlah Aluminium pada tanah yang pada perkebunan yang dikelola dengan jangka panjang menyebabkan $\mathrm{P}$ dalam bentuk orthofosfat sulit dijerap oleh tanaman mengingat $\mathrm{P}$ yang tidak mobil setelah termineralisasi. Karena sifat $\mathrm{P}$ yang tidak mobil dalam tanah, mengakibatkan pemupukan $\mathrm{P}$ tidak begitu berpengaruh pada ketersediaan $\mathrm{P}$ untuk pertumbuhan tanaman teh (Zheng et al., 2011). Selain itu, tanaman teh yang umumnya menyerap $\mathrm{N}$ dalam bentuk ammonium yang dapat menyumbang $\mathrm{H}^{+}$pada larutan tanah, akar tanaman mengambil $\mathrm{NH}_{4}{ }^{+}$dan $\mathrm{Al}^{3+}$, sehingga proton dilepaskan, dengan demikian akan terjadi pemasaman tanah (Ruan 2004) melalui mineralisasi nitrogen dengan nitrifikasi dan denitrifikasi juga menunjukkan nilai kandungan nitrogen sangat tinggi pada kedalaman $0-20 \mathrm{~cm}$ dan 20-40 cm, dengan demikian $\mathrm{H}^{+}$dapat diproduksi melalui nitrifikasi di bawah aplikasi $\mathrm{N}$ yang tinggi dan akan melepaskan banyak $\mathrm{Al}^{3+}$ melalui ikatan Al - interlayer (Yang et al., 2018).

Disamping muatan, bahan organik di dalam tanah juga akan melepaskan $\mathrm{H}^{+}$ketika termineralisasi.Sehingga mineralisasi $\mathrm{P}$ melalui hidrolisis oleh eksudat akar tanaman merupakan salah satu cara tanaman dalam menjerap $\mathrm{P}$, kemudian fosfat diserap tanaman dalam bentuk orthofosfat (Peoples et al., 2006). Setelah P termineralisasi menjadi orthofosfat, $\mathrm{P}$ menjadi tidak mobil dan terjerap sebagian oleh ikatan oksida ataupun tercuci bersama aliran opermukaan (runoff) atau leaching ke lapisan tanah yang lebih dalam.

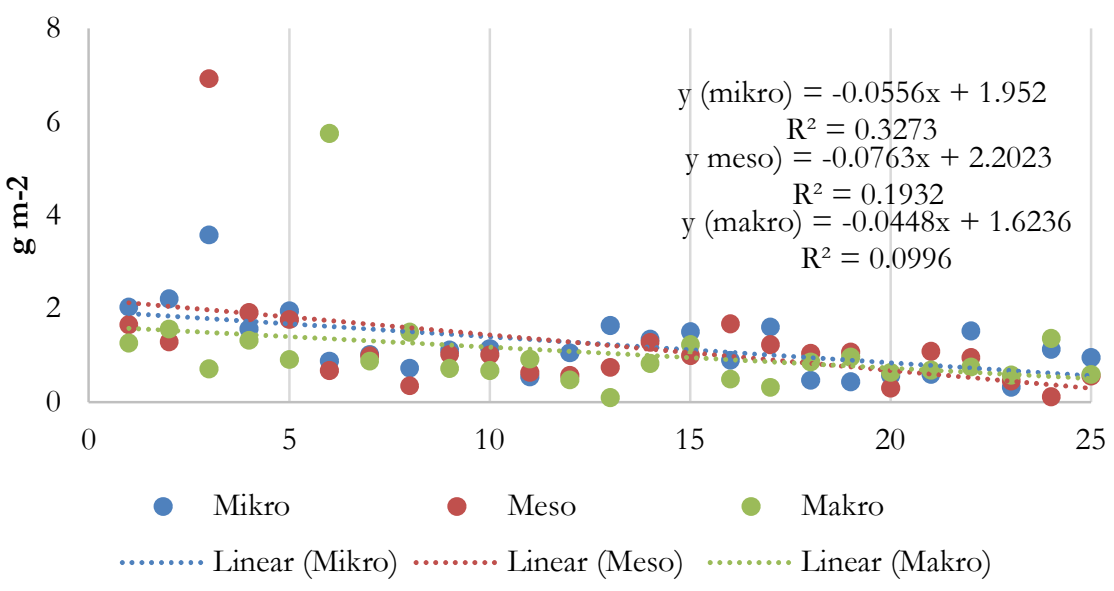

Gambar 2. Korelasi agregat tanah dengan pasokan P. 


\section{Jurnal Tanah dan Sumberdaya Lahan Vol 8 No 1: 215-219, 2021 e-ISSN:2549-9793, doi: 10.21776/ub.jts1.2021.008.1.24}

Secara umum, kelerengan dengan pasokan ketersediaan $\mathrm{P}$ pada tanah perkebunan tanaman teh tidak berkorelasi (Gambar 2), dengan persentse tingkat korelasi pada fraksi agregat secara berturut turut, $32,73 \%$ untuk mikro, $19,32 \%$ meso agggregat, dan hanya $9,96 \%$ untuk fraksi makro agregat. Dengan demikian, kelerengan tidak secara signifikan mempengaruhi langsung ketersediaan jumlah fosfat pada tanah perkebunan tanaman teh. Rendahnya jumlah ketersediaan P pada semua kelas lereng disebabkan oleh mineralisasi $\mathrm{P}$ menjadi $\mathrm{P}$ inorganik yang tidak terikat dan terlarut dalam larutan tanah.

\section{Kesimpulan}

Secara keseluruhan fosfat pada daerah perkebunan teh berada pada kriteria yang sangat rendah. Berdasarkan hasil penelitian yang diperoleh, Aluminium dan pemupukan $\mathrm{N}$ menjadi penyebab rendahnya $\mathrm{P}$ pada tanah yang mengakibatkan tingginya $\mathrm{H}^{+}$, dengan faktor kelerengan tidak secara signifikan mempengaruhi langsung ketersediaan jumlah fosfat pada tanah perkebunan teh yang berumur 36 tahun.

\section{Daftar Pustaka}

Balai Besar Litbang Sumberdaya Lahan Pertanian. 2014. Tanah Andisol di Indonesia : Karakteristik, Potensi, Kendala, dan Pengelolaannya untuk Pertanian. Bogor. 1-139 hal.

Balai Penelitian Tanah. 2005. Petunjuk Teknis : Analisis Kimia Tanah, Tanaman, Air, dan Pupuk.. Balai Penelitian dan Pengembangan Pertanian. Departemen Pertanian. 283 hal.
Garland, G., Bunneman, E.K., Oberson, A., Frossard, E., Snapp, S., Chikowo, R and Six, J. 2018. Phosphorus cycling within soil aggregate fractions of a highly weathered tropical soil: a conceptual model. Soil Biology and Biochemistry $116:$ : 91-98.

Peoples, M.B., Richardson, A.E. and Simpson, R.J. 2014. Soil: Nutrient Cycles. CSIRO Plant Industriy, Canberra, CT, Australia.

Pusat Penelitian Tanaman Teh dan Kina. 2019. Rekomendasi Pemupukan Tanaman Teh 2019 Lingkup PTPN VI. Pusat Penelitian Teh dan Kina, Gambung. 1 - 191 hal.

Pusat Penelitian dan Pengembangan Perkebunan. 2010. Budidaya dan Pasca Panen Teh. Badan Penelitian dan Pengembangan Pertanian. Kementerian Pertanian. Bogor. 1- 86 hal.

Ruan, J., Ma, L., Shi, Y. and Zhang F. 2004. Effect of litter incoorperation and nitrogen fertilization on the contents of extractable aluminum in the rhizosphere soil of tea plant (Camillia sinensis (L) O. Kuntze). Plant and Soil 263 : 283-256.

Yan, P., Chen, S., Lichao, F., Xin, L., Liping, Z, Lan, Z. and Han, W. 2018. Tea planting affects soil acidification and nitrogen and phosphorus distribution in soil. Agriculture, Ecosystems and Environment 254(2018): 20 -25.

Yang, X., Kang, N., Yuan-zhi, S., Xiao-yun. Y, Qunfeng, Z. and Li, F. 2018. Effects of long-term nitrogen application on soil acidification and solution chemistry of a tea plantation in China. Agriculture, Ecosystem and Environtment 252 : $74-82$.

Zicheng, Z., Xiaoling, H. and Tingxuan, L. 2011. Status and evaluation of the soil nutrients in tea plantation. Procedia Environmental Sciences12:45-51.

Zhu, T., Zhang J, Meng, T., Zhang, Y., Yang, J., Muller, C. and Zai, Z. 2014. Tea plantation destroys soil retention of $\mathrm{NO}_{3}{ }^{-}$and $\mathrm{N}_{2} \mathrm{O}$ increase emission in subtropical China. Soil Biology and Biochemistry 73 : $106-114$. 